\title{
Alterações oculares e eletrorretinográficas na doença falciforme
}

\author{
Ocular and electroretinographic changes in sickle cell disease
}

Renato Cunha David ${ }^{1}$, Haroldo Vieira de Moraes Júnior $^{2}$, Márcio Penha Morterá Rodrigues²

\section{RESUMO}

Objetivo: O objetivo principal desta série de casos foi obter dados eletrorretinográficos em indivíduos portadores de síndrome falcêmica. O objetivo secundário foi identificar alterações oculares, sua frequência e o estágio de evolução.

Métodos: Foram avaliados 90 portadores de doença falciforme, com idade entre 8 e 75 anos, submetidos a exame oftalmológico completo, mapeamento de retina, retinografia, angiografia fluoresceínica e eletrorretinografia. Eletrorretinogramas com amplitude da onda b inferior a $400 \mathrm{~mW}$ foram considerados subnormais. Foi realizado estudo de prevalência, utilizando o teste do Chi-quadrado, sendo $P<0,001$. Resultados: $O$ eletrorretinograma se mostrou subnormal em 27 (30\%) dos 90 pacientes, mas destes, apenas $4(4,4 \%)$ apresentavam retinopatia proliferativa. O sinal da vírgula em $95 \%$ dos indivíduos, a tortuosidade vascular retiniana em $36,6 \%$ e o "black sunburst" em 24,4\% foram as alterações mais encontradas.

Conclusão: Não foi observada correlação entre a doença falciforme e alterações eletrorretinográficas, como descrito em outros estudos. Por outro lado, os achados oculares corroboram pesquisas anteriores.

Descritores: Doença da hemoglobina SC; Retina; Doenças retinianas; Vasos retinianos; Eletrorretinografia

\section{ABSTRACT}

Purpose: The primary objective of this case series was to get electroretinographic data in subjects with sickle cell disease. The secondary purpose was to identify ocular changes, their frequency and stage of evolution.

Methods: 90 patients aged between 8 and 75 years were evaluated. They were subjected to complete ophthalmological examination, indirect ophthalmoscopy, retinography, angiography and electroretinography. Electroretinograms with amplitude of wave b less than $400 \mathrm{~mW}$ were considered subnormal. Prevalence study was conducted using the Chi-square test, $P<0.001$.

Results: The electroretinogram was subnormal in 27 (30\%) of 90 patients, but of these, only 4 (4.4\%) had proliferative retinopathy. The sign of comma in 95\% of individuals, the retinal vascular tortuosity in $36.6 \%$ and black sunburst in $24.4 \%$ were the most frequent changes.

Conclusion: No correlation between sicklecell disease and electroretinographicschanges, as described in otherstudies, werenoted. On theother hand, theocularfindings corroborate the previous researches.

Keywords: Hemoglobin SC disease; Retina; Retinal diseases; Retinal vessels; Electroretinography

\section{INTRODUÇÃO}

Dentre as anemias hemolíticas crônicas, a doença falciforme é a mais frequente e incapacitante em nosso meio. Aproximadamente $0,3 \%$ a $3 \%$ dos nascidos vivos no Estado do Rio de Janeiro, apresentam anemia falciforme e traço falcêmico, respectivamente ${ }^{(1)}$; cerca de $0,3 \%$ das crianças negras nos Estados Unidos são homozigotos $\mathrm{SS}^{(2)}$.

A anemia falciforme é caracterizada pela produção de hemoglobinas anormais que deformam e tornam rígidas as hemácias, causando o aumento da viscosidade sanguínea e oclusão da microcirculação em graus variáveis ${ }^{(3)}$. As limitações físicas por todo o organismo aumentam em frequência e intensidade com o passar dos anos. Sabe-se que suas alterações oculares têm grande incidência e podem levar à amaurose irreversível. Estas possibilitam excepcional visualização e documentação, viabilizando sua análise precisa e bem documentada. Deve-se ressaltar que os quadros oculares são de início assintomático, o que torna imperioso o exame oftalmológico completo e sob midríase dos portadores de doença falciforme.
O genótipo SS possui 90 a 100\% de hemoglobina S e apresenta maior frequência e intensidade de manifestações clínicas. Os indivíduos portadores de genótipo SC, SD e S-Tal evoluem com anemia moderada e usualmente apresentam curso clínico sistêmico benigno, com poucas crises por ano ${ }^{(4)}$. Entretanto, essa população apresenta as alterações oculares mais graves dentre as síndromes falciformes ${ }^{(5)}$. A menor ocorrência de retinopatia falciforme proliferativa em portadores de genótipo SS pode ser justificada pela anemia hemolítica grave sempre presente nestes indivíduos e assim os baixos valores de hematócrito evitariam os fenômenos vaso-oclusivos por diminuir a viscosidade sanguínea. Já nos genótipos SC, SD e S-Tal, isto não ocorre, pois a quantidade de hemácias circulantes está frequentemente próxima do normal(6). Os indivíduos com genótipo AS, AC, AD e A-Tal são considerados portadores de traço falcêmico ou transmissores, sendo de grande interesse sob o aspecto genético.

Numerosos estudos sobre a retinopatia falciforme foram realizados, principalmente após sua classificação proposta por Goldberg em $1971^{(7)}$ :
Submitted for publication: June 15, 2009

Accepted for publication: November 9, 2010

Study carried out at the Departamento de Oftalmologia do Hospital Universitário Clementino Fraga Filho - Universidade Federal do Rio de Janeiro (RJ) - Brazil.

Physician, Serviço de Oftalmologia, Hospital Municipal da Piedade; Serviço de Oftalmologia do Hospital Universitário Clementino Fraga Filho, Universidade Feder Rio de Janeiro (RJ) - Brazil.

2 Physician, Serviço de Oftalmologia, Hospital Universitário Clementino Fraga Filho da Universidade Federal do Rio de Janeiro - UFRJ - Rio de Janeiro (RJ). Brazil.
Funding: No specific financial support was available for this study.

Disclosure of potential conflicts of interest: R.C.David, None; H.V.Moraes Junior, None; M.P.M. Rodrigues, None.

Correspondence address: Renato Cunha David. Rua Henrique Cordeiro, 120 - Bloco 1 - Apto. 1.801 - Rio de Janeiro - RJ - 22631-450 - Brazil - E- mail: renadavid@gmail.com

Summary of the Master's Dissertion submitted to and approved by the Postgraduate Program in General Surgery, Faculty of Medicine, Federal University of Rio de Janeiro - UFRJ, Brazil, as part of the requirements to obtain the Master's Degree, area of focus General Surgery, Ophthalmology section.

Editorial Note: After completing the confidential analysis of the manuscript, ABO discloses, with his agreement, the name Dr. Luiz Carlos Molinari Gomes as a reviewer. We thank his effort and expertise in participating in this process. 


\section{RETINOPATIA FALCIFORME NÃO PROLIFERANTE}

- Presença de branco sem pressão próximo à ora serrata.

- Presença de manchas pigmentares escuras (intermediário entre hemorragia e "black sunburst spots").

- Presença de "black sunburst spots".

\section{RetinOPATIA FALCIFORME NÃO PROLIFERANTE}

GRAU I: Oclusão de arteríolas periféricas.

GRAU II: Anastomoses arteríolo-venulares na extrema periferia retiniana.

GRAU III: Alterações neovasculares - presença de "sea fans".

GRAU IV: Hemorragia vítrea.

GRAU V: Descolamento tracional da retina.

Entretanto, poucos alcançaram população próxima de 100 pacientes e registros associados de eletrorretinograma são ainda mais raros. A valiosa oportunidade de investigar um número significativo de portadores de doença falciforme, de várias faixas etárias, motivou o presente estudo.

O desenho de estudo realizado foi observacional transversal, de achados oculares e registros eletrorretinográficos em 90 pacientes portadores de doença falciforme (genótipos SS, SC e S-Tal). Seu objetivo principal foi avaliar indivíduos portadores de síndrome falcêmica a fim de obter dados eletrorretinográficos e o objetivo secundário foi identificar alterações oculares, a frequência e o estágio de evolução das mesmas em pacientes acometidos pela doença falciforme.

\section{MÉTODOS}

Foram avaliados 90 portadores de doença falciforme, que cadastrados com genótipo confirmado no Instituto Estadual de Hematologia Arthur de Siqueira Cavalcanti (HEMORIO) manifestaram interesse em participar da pesquisa por livre e espontânea vontade.
O exame consistiu de: anamnese, leitura do termo de livre consentimento e avaliação oftalmológica, incluindo acuidade visual corrigida, biomicroscopia, tonometria de aplanação, fundoscopia e mapeamento de retina realizado sob midríase, obtida com a instilação de tropicamida a 1\%, com oftalmoscópio binocular indireto Keeler ${ }^{\circledR}$ e lente asférica de +20 D. A avaliação oftalmológica por imagem consistiu de retinografia e angiografia fluoresceínica, com retinógrafo Topcon TRC50-VT ${ }^{\circledR}$, sob midríase, utilizando $2 \mathrm{ml}$ de fluoresceína sódica a 20\% por via intravenosa (veia cubital). A avaliação eletrorretinográfica foi realizada com aparelho Neuropack II da empresa Nihon Koden ${ }^{\circledR}$ segundo o protocolo definido pela Sociedade Internacional de Eletrofisiologia Clínica da Visão Ocular (ISCEV) de 2004, com exceção da utilização da cúpula de Ganzfield (full field) que não está disponível no Hospital Universitário Clementino Fraga Filho. Exames com amplitude de onda b superior a $400 \mathrm{~mW}$ foram considerados normais. Os restantes foram divididos em subnormais e extintos. Foi realizado tratamento dos estágios proliferativos iniciais por meio de fotocoagulação a laser de argônio, com aparelho Zeiss Visulas Argon $\|{ }^{\circledR}$. Intervenção cirúrgica quando necessária, foi realizada no Centro Cirúrgico do Hospital Universtário Clementino Fraga Filho, com vitreófago Alcon MVS e endolaser Alcon Eye lite ${ }^{\circledR}$.

Foi realizado estudo de prevalência, utilizando o teste do Chiquadrado, sendo $P<0,001$.

Os seguintes critérios de exclusão foram usados: pacientes com visão 20/200 ou menor nos dois olhos, com distúrbios psiquiátricos, com trauma ocular prévio, portadores de diabetes mellitus ou de hipertensão arterial sistêmica, portadores de qualquer retinopatia que não fosse decorrente da doença falciforme e menores de 18 anos sem a autorização dos pais.

\section{RESULTADOS}

As características da população estudada em relação ao sexo mostraram forte predominância de mulheres, com 63 (70\%) mu-

Tabela 1. Pacientes com traçado eletrorretinográfico subnormal associado à fundoscopia, genótipo, sexo, cor e idade

\begin{tabular}{|c|c|c|c|c|c|c|c|c|}
\hline Paciente $\mathrm{N} N$ & Genótipo & Sexo & Cor & Idade & ERG OD & ERG OE & FOOD & FOOE \\
\hline 4 & SS & Feminino & Negra & 28 & Subnormal & Subnormal & RFNP & RFNP \\
\hline 8 & SS & Feminino & Negra & 33 & Subnormal & Normal & RFNP & RFNP \\
\hline 13 & SS & Masculino & Negra & 28 & Subnormal & Subnormal & RFNP & RFNP \\
\hline 14 & SS & Feminino & Negra & 49 & Subnormal & Subnormal & Normal & Normal \\
\hline 21 & SS & Masculino & Negra & 30 & Subnormal & Subnormal & RFNP & RFNP \\
\hline 24 & SS & Feminino & Negra & 44 & Subnormal & Subnormal & RFNP & RFNP \\
\hline 30 & SS & Feminino & Negra & 28 & Subnormal & Subnormal & RFNP & RFNP \\
\hline 35 & SS & Masculino & Negra & 23 & Subnormal & Subnormal & RFNP & RFNP \\
\hline 36 & SS & Feminino & Negra & 17 & Subnormal & Subnormal & RFNP & RFNP \\
\hline 38 & SS & Feminino & Negra & 10 & Subnormal & Subnormal & RFNP & RFNP \\
\hline 40 & SS & Feminino & Negra & 35 & Subnormal & Subnormal & Normal & Normal \\
\hline 42 & SS & Masculino & Negra & 41 & Subnormal & Subnormal & Normal & Normal \\
\hline 50 & SS & Feminino & Negra & 50 & Subnormal & Subnormal & Normal & Normal \\
\hline 53 & SS & Feminino & Negra & 42 & Subnormal & Subnormal & RFP & RFP \\
\hline 54 & SS & Feminino & Branca & 19 & Subnormal & Subnormal & RFNP & RFNP \\
\hline 55 & SS & Feminino & Negra & 38 & Subnormal & Normal & Normal & Normal \\
\hline 60 & SS & Feminino & Negra & 41 & Subnormal & Subnormal & Normal & Normal \\
\hline 61 & SS & Feminino & Parda & 39 & Subnormal & Subnormal & Normal & Normal \\
\hline 73 & SS & Masculino & Parda & 30 & Subnormal & Subnormal & RFNP & RFNP \\
\hline 76 & SS & Feminino & Negra & 34 & Subnormal & Subnormal & RFNP & RFP \\
\hline 78 & SS & Feminino & Negra & 48 & Subnormal & Extinto & RFP & RFP \\
\hline 79 & SS & Feminino & Negra & 45 & Subnormal & Normal & RFNP & RFNP \\
\hline 88 & SS & Masculino & Negra & 18 & Normal & Subnormal & Normal & Normal \\
\hline 89 & SS & Feminino & Parda & 20 & Subnormal & Normal & Normal & Normal \\
\hline 3 & SC & Masculino & Negra & 47 & Subnormal & Subnormal & RFNP & RFNP \\
\hline 64 & SC & Masculino & Negra & 28 & Normal & Subnormal & RFNP & RFNP \\
\hline 87 & SC & Masculino & Branca & 33 & Subnormal & Normal & RFP & RFP \\
\hline
\end{tabular}

$\mathrm{RFNP}=$ retinopatia falciforme não proliferativa; $\mathrm{RFP}=$ retinopatia falciforme proliferativa; $\mathrm{ERG}=$ eletrorretinograma; $\mathrm{FO}=\mathrm{fundoscopia;} \mathrm{OD}=\mathrm{olho}$ direito; $\mathrm{OE}=\mathrm{olho}$ esquerdo 
Iheres e 27 (30\%) homens. A idade variou de 8 a 75 anos, com predominância de pacientes entre 16 e 45 anos (73,3\%) e média de 31,4 anos. Como a doença falciforme atinge predominantemente negros e seus descendentes, apenas $4(4,4 \%)$ pacientes eram de cor branca, $20(22,2 \%)$ de cor parda e $66(73,3 \%)$ negros.

Sob o aspecto genotípico, o grupo SS contribuiu com 66 (73,3\%) pacientes, enquanto que 20 (22,2\%) pacientes portavam o genótipo SC e $4(4,4 \%)$ o S-Tal.

A tabela 1 expõe os pacientes com traçado subnormal correlacionados com as outras variáveis. Os pacientes cujo eletrorretinograma se mostrou subnormal formaram um grupo de 27 pacientes (30\%), com idade entre 10 e 50 anos, média de 33,2 anos. Nestes, a alteração foi evidenciada em ambos os olhos de 19 pacientes $(21,1 \%)$, enquanto $8(8,8 \%)$ apresentaram baixa amplitude de onda b em apenas um olho.

A frequência de retinopatia falciforme foi semelhante nos três grupos, assim como na população total - mais da metade dos pacientes (Tabela 2). Com relação à forma proliferativa, 17 olhos de 14 pacientes apresentaram alterações periféricas desde anastomoses arteríolo-venulares com retina isquêmica, "sea fans" (Figuras 4 a e 4 b), até hemorragia vítrea moderada. Esses pacientes foram submetidos à laserterapia com resultado satisfatório, sem comprometimento da acuidade visual. Apenas três olhos de dois pacientes - um SS e um SC - encontravam-se em fase terminal, com descolamento de retina tracional antigo e sem possibilidade de tratamento mesmo que cirúrgico.

Como a doença falciforme é caracterizada por diminuição do fluxo sanguíneo e fenômenos oclusivos da microcirculação em graus variados, toda a vasculatura do olho pode ser afetada. Na conjuntiva, segmentos vasculares tortuosos em forma de vírgula, aparentemente isolados, revelam o sinal da vírgula (Figura 1). Este, muito frequente, mostrou-se presente em 95\% dos olhos examinados e a tortuosidade vascular retiniana (Figura 2) em 36,6\%. Os "black sunburst" (Figura 3), que correspondem à hiperplasia e hipertrofia do epitélio pigmentado da retina, secundários às hemorragias, foram encontrados em $24,4 \%$ dos exames, sendo a terceira alteração mais frequente, ratificando estudos anteriores ${ }^{(8-15)}$. A presença

Tabela 2. Frequência de retinopatia falciforme nos genótipos SS, SC e STal e na população total

\begin{tabular}{lcccc}
\hline & SS & SC & S-Tal & Total \\
\hline Sem RF & $28(42,4 \%)$ & $9(45 \%)$ & $1(25 \%)$ & $40(44,4 \%)$ \\
RFNP & $31(47,0 \%)$ & $6(30 \%)$ & $1(25 \%)$ & $36(40,0 \%)$ \\
RFP & $7(10,6 \%)$ & $5(25 \%)$ & $2(50 \%)$ & $14(15,6 \%)$ \\
\hline
\end{tabular}

$R F=$ retinopatia falciforme; $R F N P=$ retinopatia falciforme não proliferativa;

$\mathrm{RFP}=$ retinopatia falciforme proliferativa, $\mathrm{P}<0,001$

Tabela 3. Alterações oculares encontradas nos genótipos SS, SC e STal e no total de indivíduo

\begin{tabular}{|c|c|c|c|c|c|c|c|c|}
\hline & \multicolumn{2}{|c|}{ SS } & \multicolumn{2}{|c|}{ SC } & \multicolumn{2}{|c|}{$S$ tal } & \multicolumn{2}{|c|}{ Total } \\
\hline & № & $\%$ & № & $\overline{\%}$ & № & $\%$ & № & $\%$ \\
\hline Sinal da vírgula & 63 & 95,4 & 20 & 100 & 3 & 75 & 86 & 95,5 \\
\hline Atrofia iriana & 11 & 16,6 & 3 & 15 & 2 & 50 & 15 & 16,6 \\
\hline Tortuosidade vascular & 24 & 36,4 & 6 & 30 & 3 & 75 & 33 & 36,6 \\
\hline Sinal do disco & 4 & 6,0 & 3 & 15 & 0 & 0 & 7 & 7,7 \\
\hline Estrias angióides & 4 & 6,0 & 2 & 10 & 0 & 0 & 6 & 6,6 \\
\hline Depressão macular & 9 & 13,6 & 3 & 15 & 1 & 25 & 13 & 14,4 \\
\hline "Black sunburst" & 15 & 22,7 & 6 & 30 & 2 & 50 & 23 & 25,5 \\
\hline Pontos iridescentes & 7 & 10,6 & 3 & 15 & 2 & 50 & 12 & 13,3 \\
\hline Proliferação neovascular & 7 & 10,6 & 5 & 25 & 2 & 50 & 14 & 15,5 \\
\hline
\end{tabular}

de estrias angióides em 5,5\% dos casos merece ênfase em função de sua evolução natural que somada à retinopatia falciforme, aumenta o risco de seus portadores ao longo do tempo de desenvolver perda visual grave ${ }^{(16)}$. A tabela 3 relaciona as alterações oculares encontradas com os respectivos genótipos.

Os pacientes portadores de retinopatia falciforme proliferativa formam um grupo de 13 indivíduos (14,4\%) com idade entre 31 e 58 anos, média de 43 anos. O quadro se apresentou em ambos os olhos de 5 pacientes $(5,5 \%)$, enquanto $8(8,8 \%)$ tiveram um olho acometido.

Apenas os dois pacientes, já mencionados, com quadro avançado apresentaram perda visual significativa. O primeiro (genótipo SC), com visão no olho direito (OD) de 20/400 e no olho esquerdo (OE) de vultos. O segundo (genótipo SS) com acuidade visual em OD de 20/40 e sem percepção luminosa em OE. Os outros 88 indivíduos (97,7\%) apresentaram acuidade visual igual ou maior que 20/30 no melhor olho com correção máxima.

\section{DISCUSSÃO}

Dentre os vários estudos sobre a retinopatia falciforme, dois são os principais:

O Jamaica Sickle Cohort Study e outro realizado no Sickle Cell Center, Miami.

O primeiro estudou 100.000 recém-nascidos consecutivos entre 1973 e 1981. A coorte reuniu 516 falcêmicos que foram avaliados durante vinte anos. Os resultados publicados em $2005^{(17)}$ revelaram que a retinopatia falciforme proliferativa se desenvolveu em $14 \%$ dos homozigotos SS e em $43 \%$ dos genótipos SC. Além disso, a incidência da retinopatia falciforme proliferativa aumenta com a idade e sua regressão espontânea foi observada em 32\% dos casos.

O segundo foi iniciado em 1979 no Sickle Cell Center, Miami, no qual 85 pacientes completaram 6,7 anos de avaliação. Os resultados publicados em 1992 concluíram que ${ }^{(18)}$ :

1) A retinopatia falciforme apresenta agravamento com o passar dos anos em todos os genótipos.

2) Os portadores de genótipo SC, com idade entre 15 a 30 anos, merecem atenção especial em virtude de seu maior risco em desenvolver quadros oculares mais avançados.

3) A laserterapia profilática das neovascularizações periféricas deve ser bem avaliada, devido a certa tendência à involução espontânea observada nestas lesões.

Em 1987 e 1990, foram publicados os dois únicos estudos sobre a correlação entre eletrorretinografia e retinopatia falciforme ${ }^{(19,20)}$. No primeiro, a avaliação de oito indivíduos evidenciou uma dimi-

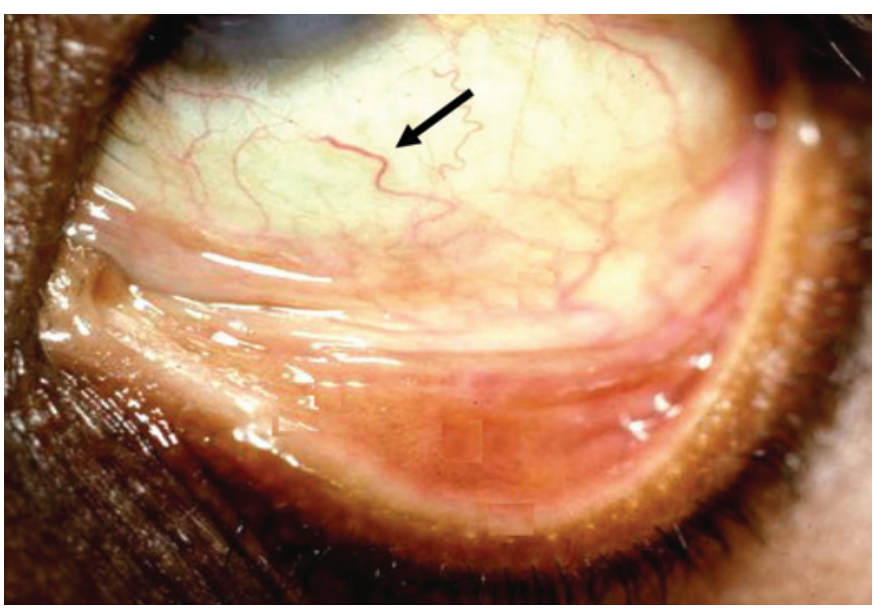

Figura 1. Sinal da vírgula (paciente 36). 
nuição da amplitude da onda b nos pacientes que apresentavam retinopatia proliferativa. Foi sugerido que o eletrorretinograma poderia ter valor no monitoramento da evolução dos pacientes falcêmicos. No segundo, com 44 pacientes, o autor obteve resultado semelhante e ratificou sua proposta.

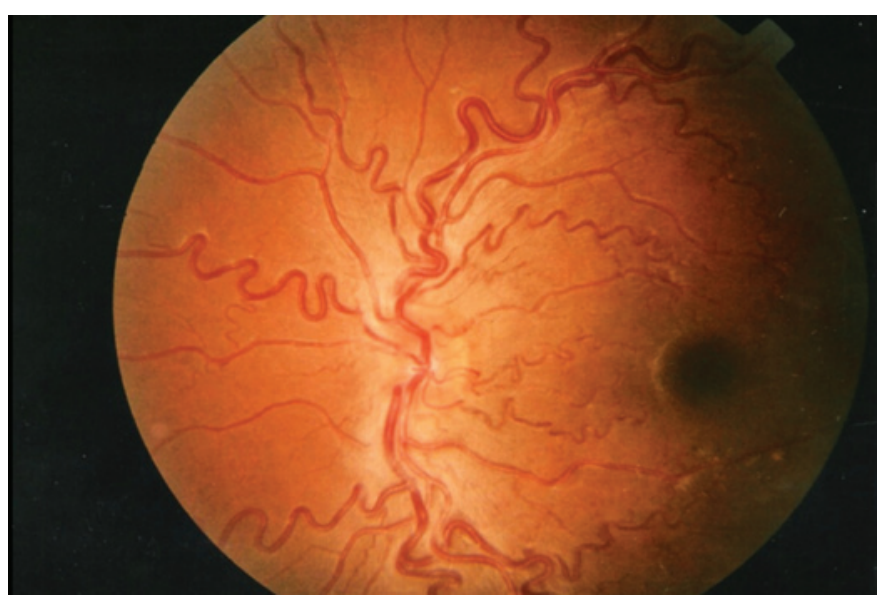

Figura 2. Tortuosidade vascular aumentada (paciente 29).

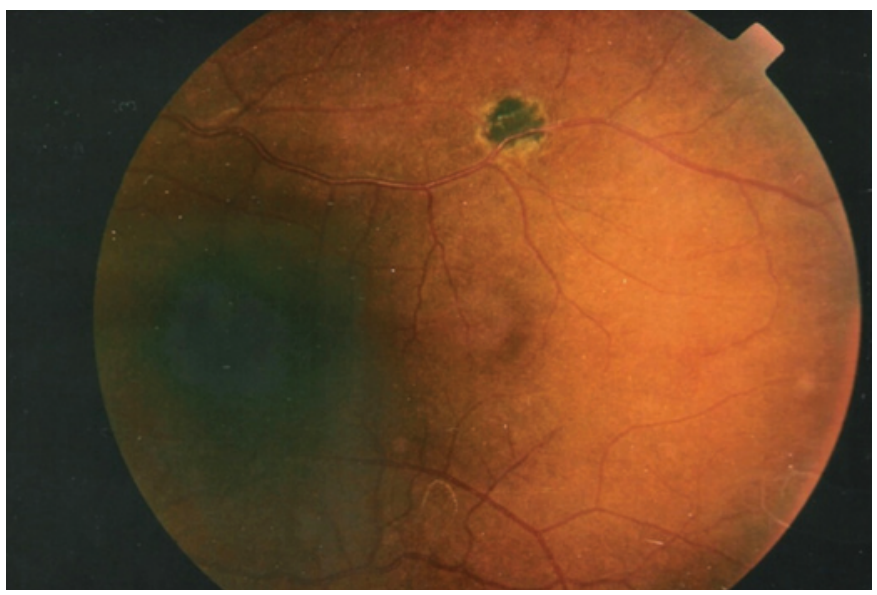

Figura 3. "Black sunburst" (paciente 7).
Sobre os resultados obtidos no presente estudo, seria esperada uma distribuição igualitária entre homens e mulheres, por se tratar de doença hereditária não ligada ao sexo. O fato de haver predominância de mulheres nesta amostra, talvez possa ser explicado pela ausência de sintomas oculares na maioria dos indivíduos, aliada à forma espontânea de inclusão na pesquisa. Sabe-se que culturalmente as mulheres têm maior costume de exames periódicos. Entretanto, as alterações oculares e eletrorretinográficas não demonstraram preferência por nenhum dos sexos.

A variável idade deve ser valorizada, uma vez que considerável quantidade de trabalhos anteriores examinou crianças ${ }^{(21-25)}$. Os achados mais frequentes por estes autores foram o embainhamento arteriolar e aumento da tortuosidade vascular. Estes estudos ratificam o fato de que a retinopatia falciforme é agravada com o passar do tempo, e por isso, seus resultados serviram apenas como referência para o presente estudo.

A variável genótipo mostrou maior número de homozigotos SS, seguidos dos SC e S-Tal respectivamente, conforme todos os estudos relacionados ${ }^{(8-15)}$

Sobre os estudos que concluíram que o eletrorretinograma seria útil no monitoramento da evolução da retinopatia falciforme ${ }^{(19,20)}$, o presente estudo obteve dados opostos. Entre os 13 pacientes portadores de proliferação sem eletrorretinograma (ERG) extinto, apenas 4 apresentaram diminuição da amplitude da onda b. O grande número de exames normais, independente do estágio de retinopatia falciforme, nos leva a supor também que a diminuição da amplitude ocorre apenas naqueles casos de comprometimento de áreas retinianas extensas.

O estudo baseado no Jamaica Sickle Cohort Study contribuiu com dados importantes em relação à incidência de retinopatia proliferativa. Entretanto, por acompanhar indivíduos dos 5 aos 26 anos, obteve idade média de 21,3 anos na data da última avaliação. Além disso, enfatizou a ocorrência ou não de proliferação, uni ou bilateralmente. Seus resultados, inegavelmente expressivos, serviram como referência ao nosso estudo e são eles ${ }^{(17)}$ :

- A retinopatia proliferativa foi evidenciada em $43 \%$ dos indivíduos SC e 14\% dos SS. Destes, 28\% foram acometidos bilateralmente e $62 \%$ unilateralmente.

- A proliferação, quando unilateral, apresenta 16\% de probabilidade de regressão espontânea; quando bilateral, a probabilidade diminui para $8 \%$.

- Baixa acuidade visual permanente é ocorrência incomum até os 26 anos.

O estudo realizado no Sickle Cell Center é sem duvida o que mais se aproxima do nosso. Ao acompanhar 150 pacientes periodicamente durante dez anos, obteve dados expressivos em popula-
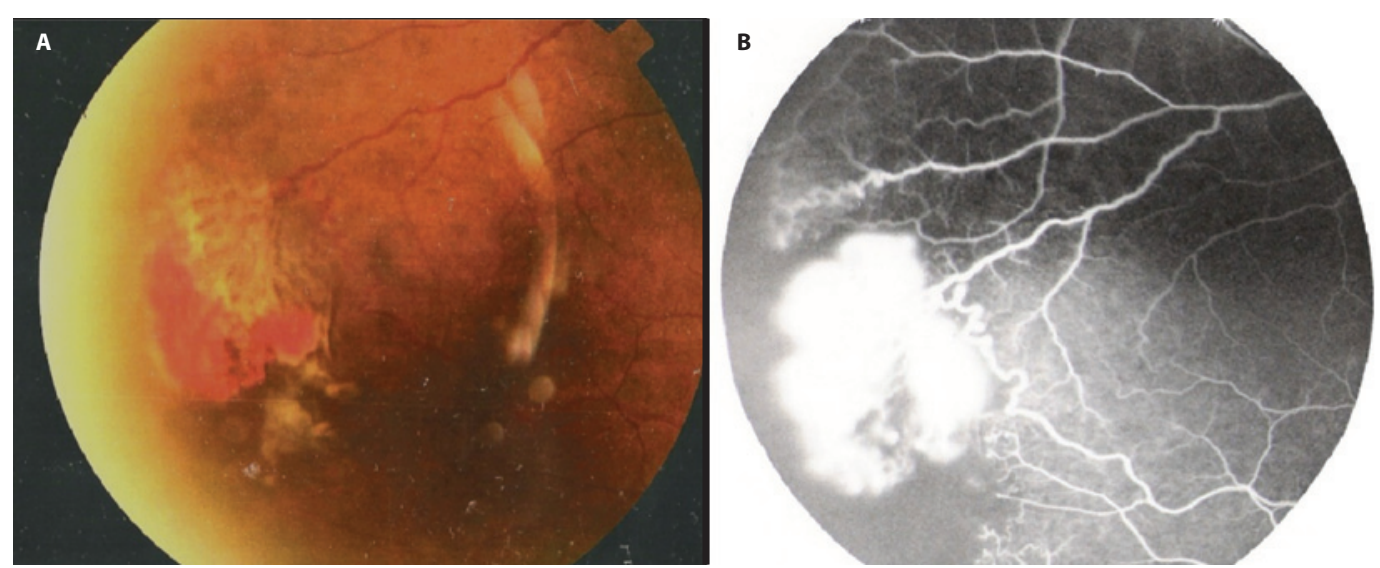

Figura 4. A) "Sea fan" (paciente 50); B) Aspecto angiográfico. 
ção com idade entre 5 e 66 anos na data do primeiro exame. Ao final da pesquisa, 85 pacientes (60 SS, 20 SC e 5 S-Tal) com idade média de 30,2 anos formaram uma amostra semelhante à nossa em todas as variáveis, permitindo assim uma comparação direta entre os dois estudos. Os resultados foram semelhantes em todos os achados, inclusive no número de olhos acometidos pelos estágios IV e $\mathrm{V}$ da retinopatia falciforme proliferativa ${ }^{(18)}$.

A alteração retiniana mais encontrada neste estudo foi o aumento da tortuosidade vascular, seguida de "black sunburst", assim como em nosso estudo.

A presença de estrias angióides em ambos os estudos foi semeIhante, em torno de 7\%. Este resultado difere do obtido por Condon e Serjean em 1976, quando os autores encontraram 22\% de 60 indivíduos homozigóticos SS com tal alteração associada. A diferença pode ser explicada pela idade da população estudada: todos os pacientes apresentavam idade de 40 anos ou mais ${ }^{(11)}$

Em 1981, alguns autores encontraram 8,6\% de estrias angióides em 241 pacientes de todas as idades, como em nosso estudo ${ }^{(16)}$

\section{CONCLUSÃO}

O estudo dos registros eletrorretinográficos nos permite concluir que o exame não fornece dados úteis para o acompanhamento de pacientes portadores de retinopatia falciforme, contrariando os dois estudos anteriores.

Por outro lado, foram confirmadas:

- A maior incidência de retinopatia falciforme proliferativa em indivíduos portadores de genótipo SC.

- A tendência evolutiva das alterações oculares.

- A frequencia de estrias angióides em 7\% dos indivíduos avaliados.

A importância do acompanhamento dos pacientes falcêmicos com o objetivo de evitar o estabelecimento de quadros avançados.

\section{REFERÊNCIAS}

1. Marra V, Moura P, Lobo P. Anemia hemolítica hereditária: I Doença falciforme. Orientações básicas aos pacientes e familiares [Internet]. Rio de Janeiro; HEMORIO;2010. [citado em 2010 Dez 12]. Disponível em: http://www.hemorio.rj.gov.br/Html/pdf/manuais_2011/ Anemia_Hemolítica_Doenca_Falciforme.pdf

2. Popma SE. Ocular manifestations of sickle hemoglobinopathies. Clin Eye Vis Care. 1996; $8(2): 111-7$.
3. Braunwald E, Fauci AS, Dasper DL, Hauser SL, Longo DL, Jameson JL. Distúrbios da Hemoglobina. In: Isselbacher K, Braunwald E, Wilson J, Martin A, Fauci AS, Kasper D, editors. Harrison Medicina Interna. 13a ed. México: Interamericana; 1995. p.1818-27.

4. Beutler E, Coller BS, Kipps TJ. The sickle cell diseases and related disorders. In: Lichtman MA editor. Williams Hematology. 15 $5^{\text {th }}$ ed. Philadelphia: Mac Graw-Hill, 1995. p.616-50.

5. Cohen SB, Van Houten PA. Hemoglobinopaties. In: Ryan SJ, editor. Retina. $2^{\underline{a}}$ ed. St. Louis: Mosby; 1994. Vol. 2. Chap.86, p.1465- 72.

6. Lee GR, Foerester J, Lukens J, Paraskevas F, Greer JP, Rodgers GM. Sickle cell anemia and other sickling syndromes. In: Lee GR, editor. Wintrobe's Clinical Hematology. $10^{\text {th }}$ ed. New York: Williams \& Wilkins, 1999. Chap. 51, p. 1346-97.

7. Goldberg MF. Classification and pathogenesis of proliferative sickle retinopathy. Am J Ophthalmol. 1971;71(3):649-65.

8. Bonamomi MT, Cunha SL, de Araújo JT. Funduscopic alterations in SS and SC hemoglobinopathies. Study of a Brazilian population. Ophthalmologica. 1988;197(1):26-33.

9. Condon PI, Serjeant GR. Ocular findings in homozygous sickle cell anemia in Jamaica. Am J Ophthalmol. 1972;73(4):533-43

10. Condon PI, Serjeant GR. Behavior of untreated sickle retinopathy. Br J Ophthalmol. 1980 64(6):404-11.

11. Condon PI, Serjeant GR. Ocular findings of eldery cases of homozygous sickle cell disease in Jamaica. Br J Ophthalmol. 1976;60(5):361-4.

12. Condon PI, Serjeant GR. Ocular findings in hemoglobin SC disease in Jamaica. Am J Ophthalmol. 1972;74(5):921-31.

13. Condon PI, Serjeant GR. Ocular findings in sickle-cell thalassemia in Jamaica. Am J Ophthalmol. 1972;74(6):1105-9.

14. Condon PI, Hayes RJ, Serjeant GR. Retinal and choroidal neovascularization in sickle cell disease. Trans Ophthalmol Soc UK. 1980;100(3):434-9.

15. Moraes HV Jr, Mello PC, Brasil OF, Oliveira MV, Cerqueira V, Turchetti R. Achados oculares em doença falciforme. Rev Bras Oftalmol. 2004;63(5/6): 299-302.

16. Hamilton AM, Pope FM, Condom PI, Slavin G, Sowter C, Ford S, et. al. Angioid streaks in Jamaican patients with homozigous sickle cell disease. Br J Ophthalmol. 1981:65(5):341-7.

17. Downes SM, Hambleton IR, Chuang EL, Lois N, Serjeant GR, Bird AC. Incidence and natura history of proliferative sickle cell retinopathy: observations from a cohort study. Ophthalmology. 2005:112(11):1869-75.

18. Clarkson JG. The ocular manifestations of sickle-cell disease: a prevalence and natural history study. Trans Am Ophthalmol Soc. 1992;90:481-504

19. Peachey NS, Charles HC, Lee CM, Fishman GA, Cunha-Vaz JG, Smith RT. Electroretinographic findings in sickle cell retinopathy. Arch Ophthalmol. 1987; 105(7):934-8.

20. Peachey NS, Gagliano DA, Jacobson MS, Derlacki DJ, Fishman GA, Cohen SB. Correlation of electroretinographic findings and peripheral retinal nonperfusion in patients with sickle cell retinopathy. Arch Ophthalmol. 1990; 108(8):1106-9.

21. Talbot JF, Bird AC, Maude GH, Acherson RW, Moriarty BJ, Serjeant GR. Sickle cell retinopathy in Jamaica children: further obsenvations from a cohort study. Br J Ophthalmol. 1988; 72(10):727-32.

22. Talbot JF, Bird AC, Serjeant GR, Hayes RJ. Sickle cell retinopathy in young children in Jamaica. Br J Ophthalmol. 1982:66(3):149-54.

23. Garcia CA, Fernandes MZ, Uchôa UB, Cavalcante BM, Uchôa RA. Achados fundoscópicos em crianças portadoras de anemia falciforme no Estado do Rio Grande do Norte. Arq Bras Oftalmol. 2002;65(6):615-8

24. Gonçalves JC, Braga JA, Nione AS, Simoceli RA, Yamamoto M. Retinopatia falciforme em Crianças. Arq Bras Oftalmol. 1990;53(4):158-61.

25. Eruchalu UV, Pam VA, Akuse RM. Ocular findings in children with severe clinical symptoms of homozygous sickle cell anaemia in Kaduna, Nigeria. West Afr J Med. 2006;25(2):88-91.

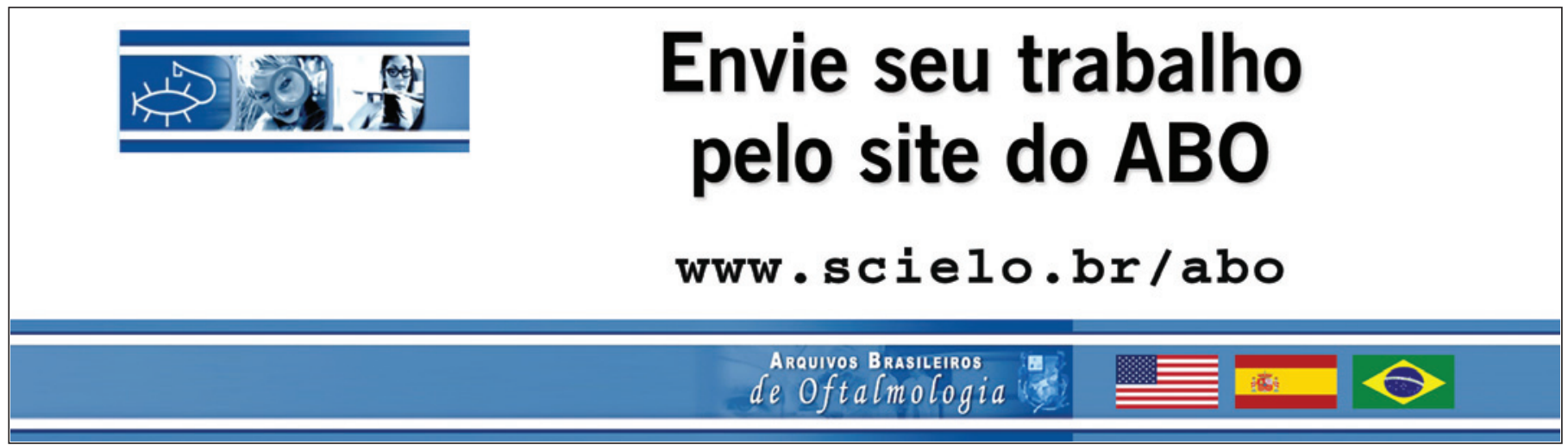

